\title{
Aproveitamento dos resíduos da colheita florestal: estado da arte e oportunidades
}

\author{
Use of forest harvest residues: state of the art and opportunities \\ Uso de residuos de cosechas forestales: estado del arte y oportunidades
}

Recebido: 19/01/2021 | Revisado: 23/01/2021 | Aceito: 27/01/2021 | Publicado: 03/02/2021

\author{
Erick Phelipe Amorim \\ ORCID: https://orcid.org/0000-0002-8964-0770 \\ Universidade Federal de São Carlos, Brasil \\ E-mail: erick.amorim95@hotmail.com \\ Alexandre Santos Pimenta \\ ORCID: https://orcid.org/0000-0002-2134-2080 \\ Universidade Federal do Rio Grande do Norte, Brasil \\ E-mail: aspimenta@ufrnet.br \\ Elias Costa de Souza \\ ORCID: https://orcid.org/0000-0001-9514-635X \\ Universidade de São Paulo, Brasil \\ E-mail: eliasrem@hotmail.com
}

\begin{abstract}
Resumo
O presente trabalho teve como objetivo apresentar uma revisão da literatura sobre a utilização de resíduos de colheita florestal como fonte de biomassa, desde a geração até a ponta final de consumo. Objetivou também elencar as principais espécies florestais plantadas no Brasil com potencial de produção de resíduos e, ainda, abordar a quantificação, qualificação dessa biomassa e as tendências do mercado para o seu aproveitamento e utilização em forma de produtos de maior valor agregado. Entende-se como resíduos de colheita florestal, tudo aquilo o que é deixado no campo após a retirada dos troncos por diferentes tipos de máquinas, incluindo cascas, folhas, galhos e ponteiras. Além de apresentar as estratégias de colheita florestal, este trabalho de revisão mostra as técnicas passíveis de serem utilizadas na conversão dos resíduos da mesma em produtos comercializáveis.
\end{abstract}

Palavras-chave: Gerenciamento de resíduos; Mecanização florestal; Energia da biomassa; Biochar.

\begin{abstract}
The present review of literature aimed to present the use of forest harvest wastes as source of biomass, since their generation to the possible end uses. Aimed still, list the main forest species grown in Brazil with potential to produce harvest wastes and, also, address the quantification and qualification of such biomass, and the market trends to their harnessing and utilization as high-value added products. Forest harvest wastes are the biomass left in the field after the collection of the wood trunks as logs and they include bark, leaves and treetops. Besides presenting the techniques of forest harvesting, this review shows the techniques to harness the harvest wastes and turn them into marketable products.
\end{abstract}

Keywords: Waste management; Forest mechanization; Biomass energy; Biochar.

\section{Resumen}

Este estudio tuvo como objetivo presentar una revisión de la literatura sobre el uso de residuos de cosechas forestales como fuente de biomasa, desde la generación hasta el consumo final. También tuvo como objetivo enumerar las principales especies forestales plantadas en Brasil con potencial para la producción de residuos y, también, abordar la cuantificación, calificación de esta biomasa y las tendencias del mercado para su uso y uso en forma de productos de mayor valor agregado. Los residuos de la cosecha forestal son todo lo que queda en el campo después de que los troncos son removidos por diferentes tipos de maquinaria, incluyendo corteza, hojas, ramas y puntas. Además de presentar las estrategias de aprovechamiento forestal, este trabajo de revisión muestra las técnicas que se pueden utilizar en la conversión de sus residuos en productos comercializables.

Palabras clave: Gestión de residuos; Mecanización forestal; Energía de biomasa; Biochar.

\section{Introdução}

A exploração da madeira é uma atividade no setor florestal produtivo devendo ser bem planejada e gerida, de forma a garantir a qualidade dos serviços e produtos, pois, quando não executada de forma adequada, pode comprometer a produtividade e elevar os custos operacionais e de produção, colocando em risco todo o trabalho silvicultural realizado e 
comprometer as atividades posteriores (Rodrigues, 2018).

As indústrias florestais geram resíduos significativos desde colheita florestal até o produto final e podem ser considerados como uma importante fonte de biomassa (Motghare et al., 2015; Pincelli et al., 2017; Ayer \& Dias, 2018). Na indústria, por exemplo, 63,3\% dos resíduos florestais podem ser destinados à geração de energia por meio da queima em caldeiras, que geram vapor e, eventualmente, energia elétrica para o processo produtivo. Além disso, resíduos como cavacos e serragem são reutilizados como matéria-prima por outras empresas do setor e representa $29,4 \%$ do total dos resíduos da indústria (IBÁ, 2019).

Os resíduos de colheita são uma atraente matéria-prima de biomassa para a produção de bioenergia (Thiffault et al., 2015). Os resíduos da colheita podem ser usados para energia como subprodutos em forma fresca (cavacos) ou densificada (briquetes e pellets), alternativas de utilização que podem adicionar renda às ao manejo florestal. Isto é especialmente aplicado quando se considera o baixo valor dos resíduos e a transformação destes em briquetes ou pellets que são biocombustíveis potencialmente competitivo e com valor agregado (Dulys-Nusbaum et al., 2019).

No Brasil, atualmente, são geradas aproximadamente 30 milhões de toneladas de resíduos de madeira, e deste total, a indústria madeireira contribui com $91 \%$ dos resíduos (Oro, 2015). No aproveitamento da biomassa oriunda de povoamentos florestais, aproximadamente $20 \%$ de todo o volume da floresta compõe-se de resíduos que normalmente permanecem nas florestas (SFB, 2012). Esses resíduos gerados na floresta podem chegar a valores de 30 a 35\% do volume de madeira produzido, sendo que apenas algo em torno de 5\% desse volume é destinado para fins energéticos.

Um estudo realizado em parceria entre a Universidade federal de Viçosa e a empresa Arcelor Mittal Bio-Florestas, com o intuito de avaliar o potencial do aproveitamento dos resíduos de biomassa e sua combustão para geração de energia elétrica, apontou que cerca de $25 \%$ da casca é perdida durante a movimentação, o processo envolve o corte, derrubada, extração, empilhamento e secagem da madeira (LIPPEL, 2014), sendo necessária a adoção de medidas para utilização deste resíduo, o que é vantajoso, dos pontos de vistas técnico e ambiental.

Tendo como base nos pontos elencados acima, o objetivo deste trabalho foi abordar a utilização de resíduos florestais como fonte de biomassa, desde a geração até a ponta final de consumo, abordando nesse contexto, as principais espécies produtoras de resíduos e, ainda, a quantificação, qualificação dessa biomassa, e as tendências do mercado para o seu aproveitamento e utilização.

\section{Metodologia}

O presente trabalho trata-se de uma revisão de literatura, classificada como uma pesquisa documental qualitativa (Pereira et al., 2018). A pesquisa foi realizada através da análise de artigos, dissertações e teses disponíveis em repositórios digitais abertos à comunidade acadêmica, utilizando as seguintes plataformas: Google acadêmico, portal de periódicos CAPES e SCIELO. Para tal, foram utilizadas as palavras-chave: "Gerenciamento De Resíduos Florestais", "Mecanização Florestal", "Resíduos Da Colheita Florestal". Após a leitura e avaliação dos artigos, foram selecionados os documentos de maior interesse do ponto de vista técnico-científico para complementar as discussões mais recentes da área de colheita florestal.

\section{Biomassa e Resíduos Florestais: Perspectivas de Utilização no Brasil e no Mundo}

A evolução do consumo de energia baseada em combustíveis fósseis conduziu a humanidade para uma matriz energética insegura, com alto custo e com impacto negativo para o meio ambiente. Isso tem levado muitos países a considerarem a necessidade de profundas mudanças, incluindo o desenvolvimento de processos mais sustentáveis e a intensificação do aproveitamento de outras fontes energéticas renováveis Tomaz et al. (2017). De acordo com Santiago \& Rezende (2013), o uso de resíduos florestais como insumo energético é uma tendência e vem despertando interesse tanto de 
países em desenvolvimento, como de países desenvolvidos e industrializados devido ao seu potencial renovável e possibilidade de redução da dependência de combustíveis fósseis, combinada à redução de emissões atmosféricas de gases causadores do aquecimento global.

Embora o interesse na implementação de projetos de uso de energia dos resíduos da colheita florestal tenha aumentado em anos recentes, poucas pesquisas estão disponíveis envolvendo a caracterização de diferentes tipos de biomassa gerados a partir da atividade de colheita diretamente ou como subprodutos, que possam ser aproveitadas para agregação de valor à atividade florestal. Embora essa não seja uma área de pesquisa completamente explorada, vem se tornando de amplo conhecimento que o uso desses resíduos, independentemente da estratégia escolhida, pode ter consequências positivas cruciais nos aspectos econômicos e ambientais para a sociedade envolvida (Jin \& Sutherland, 2018).

Estima-se que no ano de 2017, foram gerados cerca de 47,8 milhões de toneladas de resíduos de biomassa, oriundas das indústrias de base florestal, incluindo casca, galhos, folhas, cavacos, serragem e aparas de madeira que são possíveis de serem reaproveitados especialmente para a geração de energia (Ferreira et al., 2019). No ano de 2018, o setor florestal gerou 52 milhões de toneladas de resíduos sólidos, sendo que desse total, 36,9 milhões (70,9\%) foram gerados pelas atividades florestais e 15,1 milhões $(29,1 \%)$ pelas operações industriais. Dos resíduos gerados na atividade de colheita florestal, 98\%, principalmente cascas, galhos e folhas são mantidos no campo para proteção e fertilidade do solo (IBÁ, 2019). Um total de 19 milhões m3 de madeira e resíduos florestais foram produzidos no Brasil em 2018 (FAO, 2018), com grande potencial de geração de energia térmica ou elétrica (Borges et al., 2016).

As florestas têm sido uma importante fonte de energia em toda história humana. As formas tradicionais de biocombustíveis florestais são a lenha e o carvão vegetal, os quais são usados para aquecimento, cocção e proteção contra insetos e animais. De acordo com a FAO (2018), a utilização da madeira como biomassa ainda é a fonte mais importante para a geração de energia renovável, fornecendo cerca de 6\% de energia primária global. Atualmente, cerca de 3 bilhões de pessoas dependem da lenha e do carvão para as atividades domésticas. Na África e Ásia esse combustível representa 95\% da energia total consumida (WHO, 2016). Na década de 1970, a produção global foi de 2 bilhões de metros cúbicos evoluindo para 2,6 2,6 bilhões de metros cúbicos no início da década de 2000. De acordo com o banco de dados organização, a projeção é de 3,8 bilhões de metros cúbicos até 2030, representando um aumento de 100\% em relação à década de 1970.

Para o melhor entendimento da compreensão da relevância no setor energético nacional, é primordial que se entenda a definição de biomassa. O emprego da biomassa do ponto de vista energético é definido por Souza (2015), como toda matéria orgânica, vegetal ou animal que pode ser empregada para a geração de energia. De acordo com LIPPEL (2014) no Brasil, grande parte dos resíduos gerados pela colheita da madeira são abandonados no campo, onde ocorre a ciclagem de seus nutrientes, no entanto, há um alto potencial de utilização desse resíduo para a geração de energia, que pode ser obtida através da combustão direta ou da incineração, além da produção de produtos densificados da biomassa, como pellets e briquetes para combustão futura. Dados da Agência Nacional de Energia Elétrica (ANEEL, 2016), o Brasil possui um total de 523 usinas de produção energética em operação, cuja fonte de geração é a biomassa que totalizam $14.019 .781 \mathrm{~kW}$ de potência registrada. A Tabela 1 demostra os tipos de biomassa que constituem a fonte de calor em uso nas 523 usinas em operação no país, de acordo com os dados da ANEEL (2017). 
Tabela 1. Tipos de biomassa que são empregadas nas indústrias brasileiras e seu potencial de utilização.

\begin{tabular}{ccccc}
\hline Fonte & Quantidade & Potência outorgada & Potência fiscalizada & (\%) \\
\hline Floresta & 87 & 2.803 .847 & 2.547 .523 & 20 \\
Resíduos Sólidos & 14 & 88.213 & 83.699 & 0,63 \\
Resíduos animais & 10 & 1924 & 1924 & 0,01 \\
Biocombustíveis Líquidos & 2 & 4350 & 4350 & 0,03 \\
Agroindústria & 410 & 11.121 .446 & 10.775 .515 & 79,33 \\
\hline Total & 523 & 14.019 .781 & 13413.012 & 100 \\
\hline
\end{tabular}

Fonte: Adaptado de ANEEL (2017)

$\mathrm{Na}$ Tabela 1 são apresentadas as quantidades e as potências (outorgadas e fiscalizadas) dos diferentes resíduos utilizados nas indústrias do Brasil. Além do Brasil, prevê-se que, também na Europa, a promoção de energia renovável aumente drasticamente a demanda por biomassa lenhosa (Lauri et al. 2012), resultando em um cenário em que a demanda excede a oferta (Jonsson, 2013). Já existem evidências de que nesse continente, as atividades florestais estão aumentando para atender à crescente demanda por biomassa lenhosa (Buonocore et al. 2014). As previsões são que à medida que aumenta o valor das florestas que fornecem matéria-prima para bioenergia, mais terras serão convertidas em plantações de árvores de rápido crescimento para atender à demanda por celulose, setor que compete diretamente com os plantios florestais para energia. As máquinas precisarão ser rentáveis para a colheita biomassa, e uma quantidade maior dessas máquinas será necessária para atender às áreas em expansão.

Estudos de Kraxner et al. (2013) mostraram que, sob uma alta demanda global por bioenergia, a biomassa seria principalmente obtida pela conversão de florestas não gerenciadas em florestas gerenciadas, ou de novas plantações de rápido crescimento, ou otimizando o uso das terras existentes. As plantações são mais adequadas do que as florestas naturais para a produção de biomassa, pois são estabelecidas de forma lógica e planejada em terras de alta produtividade, possuem boa infraestrutura e são colhidas por sistemas tecnologicamente eficientes. Além disso, tudo, incluindo o tronco e os resíduos, toda a árvore pode ser utilizada maximizando o seu valor potencial para um valor real.

A previsão é que a demanda por madeira atinja 6 bilhões de $\mathrm{m} 3$ até 2050, tendo como principal fonte a expansão das plantações industriais (McWay, 2020). As razões para esse aumento da demanda são variadas, mas incluem o aumento do consumo de madeira em países em crescimento (Índia, Brasil e China, por exemplo); aumento do crescimento populacional, extração ilegal de madeira e conversão de terras para a agricultura em áreas tropicais, o que resultará na redução de áreas de florestas naturais e, portanto, no aumento da dependência de florestas plantadas. As razões para o estabelecimento de plantações de madeira são numerosas e variadas. As plantações existentes foram desenvolvidas para satisfazer uma demanda por determinados produtos de madeira (Zhang et al., 2015). Tradicionalmente no mundo, as principais razões para o estabelecimento de plantações florestais eram o fornecimento de fibra de madeira de baixo custo aos setores de madeira serrada, polpa e papel e painéis de madeira. Entretanto, a partir da década de 1990 consolidou-se o plantio de florestas dedicadas exclusivamente à produção de madeira para energia. No Brasil, diferentemente do resto do mundo, as florestas energéticas dedicadas à produção de carvão vegetal vêm sendo plantadas em larga escala desde a década de 1970.

\section{Colheita Florestal: Estratégias e Principais Tipos de Máquinas Utilizadas}

Na colheita florestal, várias estratégias podem ser empregadas para a extração da madeira. Um dos mais utilizados é o 
sistema de toras curtas (cut-to-length), que consiste no desgalhamento, destopamento, traçamento e descascamento. Essa última fase é opcional e realizada na própria área de plantio, originando resíduos que podem ser utilizados para geração de bioenergia e também para enriquecer o site como fonte de matéria orgânica e nutrientes. A colheita e o processamento de subprodutos de biomassa são reconhecidos como fontes viáveis e de baixo custo para geração de bioenergia (Chang et al., 2019). Esses resíduos podem suprir uma parte importante da demanda por energia térmica e elétrica das indústrias florestais brasileiras, especialmente em cenários de aumento dos custos de insumos e preocupações com as emissões de carbono dos combustíveis fósseis (Schwerz et al., 2019). No entanto, é necessário entender as características físico-energéticas desses resíduos para melhor utilizá-los após a colheita florestal (Roque et al., 2019; Sette Jr et al., 2018), principalmente devido à diversidade de biomassa que compõe os resíduos (casca, madeira, folhas) e do fato de que cada uma delas possui características distintas. A maioria dos resíduos da colheita florestal gerada no Brasil provém de florestas plantadas com diferentes espécies, como híbridos e clones de eucalipto, que ocupam uma área de 5,7 milhões de hectares, ou 75\% da área total de floresta plantada (IBÁ, 2020). Isso quer dizer que cada tipo de floresta tem uma destinação específica, seja para celulose e papel, painéis de madeira e carvão vegetal para bioenergia, o que depende da demanda (Lahr et al., 2017).

Segundo Malinovski et al. (2014), a produtividade das operações de colheita da madeira sofre influência de diversos fatores, como: localização geográfica e extensão da área de trabalho; aspectos climáticos; capacidade de suporte do terreno; relevo; características do povoamento; capacitação do operador, dentre outros. Sistema de colheita da madeira é definido por Machado (2014), como um conjunto de atividades integradas entre si, que proporcionam um fluxo constante e visando sua máxima utilização, e consequentemente, evitando os pontos de estrangulamento. A seguir são apresentados os principais sistemas de colheita da madeira com suas principais características, vantagens e desvantagens de acordo com os levantamentos realizados por Oro (2015).

\subsection{Sistema de colheita de toras curtas (cut-to-length)}

Neste sistema, a árvore é derrubada e processada ainda no interior do povoamento, sendo em seguida, extraída para a margem do talhão ou pátio temporário na forma de toras de até 6 metros de comprimento.

Vantagens:

- $\quad$ Necessita de um menor grau de mecanização;

- menor impacto ao solo;

- menor exportação de nutrientes devido a biomassa residual permanecer no talhão;

- Facilidade na execução do desbaste e menor demanda de espaço para estocagem de madeira.

Desvantagens:

- Menor produtividade;

- Maior custo devido o maior manuseio da madeira;

- Dificuldade no aproveitamento da biomassa residual que fica espalhada no talhão.

\subsection{Sistema de árvore inteira (full-tree)}

Neste sistema, as árvores são derrubadas, desgalhadas e destopadas no interior do talhão, e em seguida, a madeira na forma de fuste é arrastada para a margem do talhão ou para a execução do processamento da madeira.

Vantagens:

- Maior eficiência operacional quando comparado ao sistema anterior;

- Menor custo de produção e boa aplicação em terrenos acidentados.

Desvantagens: 
- Necessita de um planejamento e organização mais detalhada das operações;

- Planejamento mais detalhados das operações;

- Necessita de maior grau de mecanização;

- Maior impacto no solo em termos de compactação e erosão.

De acordo com Oro (2015), existem outras três formas de coletar a árvores: sendo elas: Sistema de coleta de árvores longas (tree-length); árvores completas (whole-tree), e o sistema de cavaqueamento (chipping), porém são menos utilizados devido ao impacto que os sistemas causam sobre o solo (compactação e extração de nutrientes) e por necessitar de muitas etapas para a coleta.

\section{Potencial de Utilização dos Resíduos de Colheita Florestal}

A utilização dos resíduos florestais como fonte de matéria-prima para a geração de novos produtos, agregando valor e inovação dos subprodutos, altera a ideia de que os resíduos servem apenas como material combustível. A utilização de resíduos florestais na indústria de processamento de madeira, além de reduzir a pressão de exploração de novas áreas e novas árvores, proporciona novas oportunidades de empreendedorismo dentro do manejo florestal e das práticas silviculturais, contribuindo com o crescimento de renda, criando uma nova cadeira de produção com valor agregado e colaborando para a conservação da biodiversidade (Braz et al., 2014)

Com a crescente pressão ambiental contra a exploração irracional das florestas naturais associadas à escassez de madeira e a alta dos preços desse produto no mercado internacional, a utilização total dos recursos provenientes das florestas plantada e sua ocupa hoje lugar de destaque. Dentro desse paradigma, o uso tecnológico da árvore inteira vem se firmando como tendência dominante. Essa mudança de conceito acarretou fortes pressões para que os países e empresas busquem estratégias alternativas de uso racional dos recursos florestais, através do uso tecnologia adequada às condições regionais, reduzindo desperdícios, aumentando a rentabilidade, a geração de emprego e renda. Assim, reduz-se a pressão sobre os recursos florestais nativos, reduzindo a intensidade de exploração desses recursos, com as consequentes melhorias da qualidade ambiental e social devido ao aumento de áreas florestadas (Braz et al., 2014).

Conforme discutido anteriormente no presente trabalho, a geração de resíduos florestais com desperdício ocorre ao longo de toda a cadeia produtiva, desde a colheita até a obtenção do produto final, sendo essas perdas mais significativas durante a colheita das árvores. Muitos estudos relacionados ao aproveitamento de resíduos têm como foco a utilização da madeira descartada durante o processo de desdobro mecânico de toras em serrarias, mas ao acompanhar o processo de colheita florestal, observa-se que o volume de madeira da copa das árvores que fica em campo é significativo e, portanto, o aproveitamento racional desse resíduo pode proporcionar um novo tipo de processo produtivo (Pontes et al., 2012). Por outro lado, o que impede muitas vezes o desenvolvimento de uma nova cadeia de produção é o grande volume da biomassa (galhos e copas das árvores) deixados na floresta junto com o baixo valor agregado desses resíduos in natura no local onde são coletados. Portanto, devem ser consideradas necessariamente formas eficientes de agregar valor a esses materiais, transformando-os em produtos de qualidade.

No Brasil, os estudos que avaliam o potencial de resíduos de um processo produtivo serem empregados em outros setores ainda são escassos, existindo pouca informação científica e estudos direcionados para o tema. Entretanto, alguns trabalhos evidenciam que a utilização de resíduos de colheita florestal traz benefícios para a sociedade e movimenta a economia. Por exemplo, um estudo realizado no estado do Pará em 2014, na comunidade pedreira na floresta nacional de Tapajós - Coomflona, reabriu uma unidade moveleira comunitária, retomando-se a fabricação de produtos de madeira, utilizando apenas madeira de galhos. Resíduos estes que não tinham uma destinação correta até o surgimento dessa iniciativa. 
Atividades prévias como adequação de volume específico de galhos permitiu o licenciamento ambiental da atividade. Essa cooperativa recebeu a certificação FSC - Forest Stewardship Council. De acordo com a gestão da mesma o potencial de faturamento da atividade é de 560 mil dólares anuais. Segundo estimativas do Instituto Chico Mendes de Conservação da Biodiversidade (ICMBIO, 2014), o crescimento da estratégia citada acima pode gerar renda através da criação de empregos para 80 famílias e ultrapassar 950 mil dólares anuais.

Os resíduos gerados durante a colheita da floresta são compostos principalmente de madeira, casca de árvores e copas de árvores (Grodsky et al., 2016). Além disso, a maior parte da utilização da madeira (painéis de madeira, celulose e papel) depende da remoção da casca de toras durante o processo de industrialização (Oliveira et al., 2015). Assim, a casca é um resíduo significativo do processamento de madeira nesses segmentos (Sette Jr et al., 2018). Da mesma forma, uma quantidade significativa de resíduos de madeira pode ser gerada tanto durante a colheita florestal quanto no processamento industrial da madeira (fase de serragem).

Ao estimar a massa de resíduos de um plantio de Eucalyptus grandis x Eucalyptus urophylla aos 79 meses, Castro et al. (2017) verificaram que há uma maior predominância de resíduos de madeira representando 88,33\% do total de resíduos encontrados sobre o solo e um total de 145, 99 t ha-1 de resíduos de colheita florestal no plantio. Os dados do estudo de quantificação de resíduos oriundos da colheita florestal podem ser observados de acordo com a Tabela 2.

Tabela 2. Estimativa de estoque de biomassa média por árvore e por hectare total e nas partes dos resíduos oriundos de colheita florestal

\begin{tabular}{ccccccc}
\hline Estimação & Madeira* $^{*}$ & Casca & Galhos & Folhas & Pontas** & Total \\
\hline $\begin{array}{c}\text { Biomassa } \\
\left.\text { Kg árvore }^{-1}\right)\end{array}$ & 96,45 & 8,00 & 2,43 & 1,92 & 0,39 & 109.19 \\
${\text { Biomassa }\left(\mathbf{t ~ h a}^{-\mathbf{1}}\right)}$ & 128,95 & 10,69 & 3,25 & 2,57 & 0,52 & 145,99 \\
Biomassa (\%) & $88,33 \%$ & $7,32 \%$ & $2,23 \%$ & $1,76 \%$ & $0,35 \%$ & $100 \%$ \\
\hline
\end{tabular}

* Total de madeira excluindo as ponteiras;

** Pontas: resíduos contabilizados com menor de 3 centímetros;

Fonte: Adaptado de Castro et al. (2017).

Na Tabela 2 são apresentados os valores estimados do estoque de biomassa em diferentes partes das árvores, com os dados calculados tanto para um único indivíduo, quanto para os dados estimados por área. Castro et al. (2017) apontam o potencial uso dos resíduos de colheita florestal para geração de energia elétrica que podem ser utilizados na própria indústria, sendo uma alternativa altamente interessante do ponto de vista econômico nas indústrias. Na Figura 1, é possível observar a quantidade de energia gerada na carbonização da biomassa de resíduos de colheita florestal visando o uso para a geração de energia elétrica. 
Figura 1. Potencial energético dos resíduos de colheita florestal para a geração de energia elétrica para a madeira de Eucalyptus grandis x Eucalyptus urophylla aos 79 meses em que (a) resíduos provenientes de madeira e materiais lenhosos e (b) carvão vegetal e resíduos de carbonização.

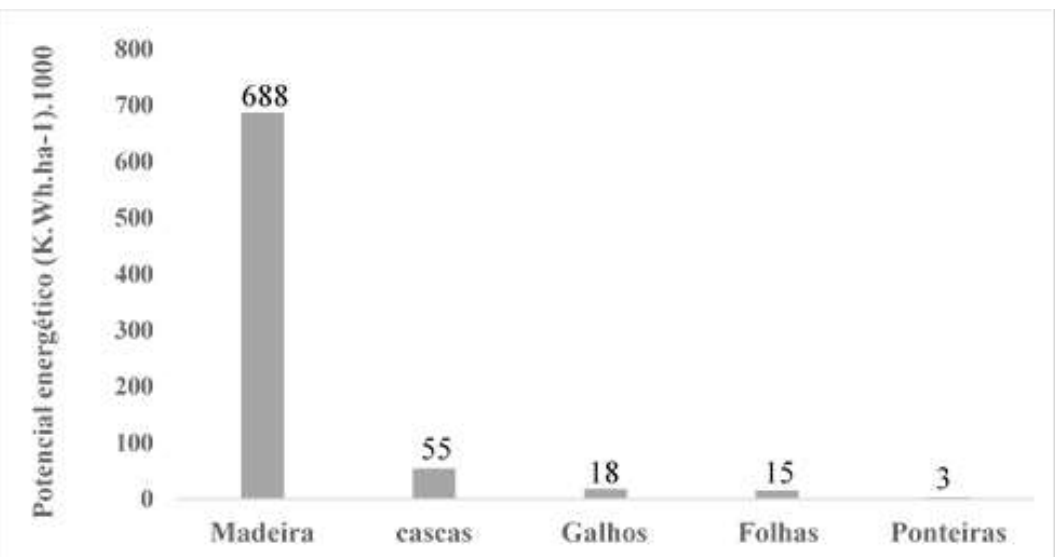

(a)

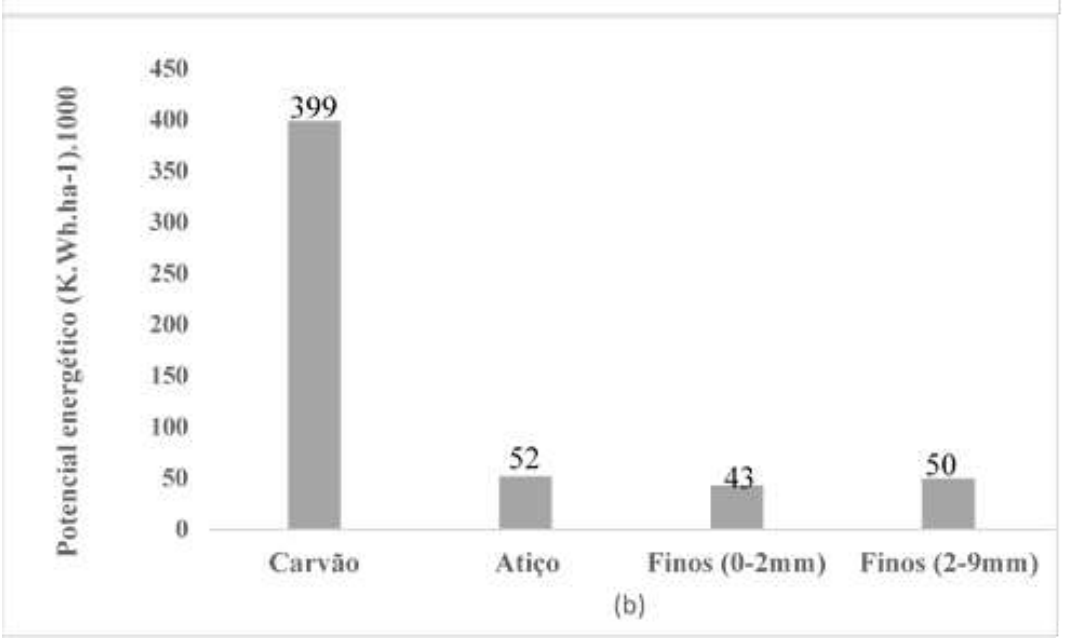

Fonte: Adaptado de Castro et al. (2017).

Na Figura 1 são apresentados os potenciais de geração de energia dos diferentes resíduos florestais, onde a madeira se destaca dos demais materiais considerados resíduos e apresenta os maiores valores de potencial energético. A exportação de nutrientes pela colheita é um dos fatores a ser considerado quando há preocupação com a manutenção da produtividade dos sítios, principalmente em solos de baixa fertilidade. As explorações intensivas em rotações curtas, sem previsão de um período mínimo necessário para reposição de nutrientes, têm sido apontadas como as maiores responsáveis pelo esgotamento do solo. Hoje, a maioria cultivadores florestais estão cientes sobre as maiores vantagens em deixar os resíduos florestais no solo, inclusive a casca. Mas a ausência de um bom planejamento no uso desses resíduos deixados no campo, bem como desconhecimento científico sobre seu comportamento têm resultados citados por Foelkel (2015):

- Problemas em termos de competição por nitrogênio para sua degradação;

- Efeitos alelopáticos para as recém-plantadas;

- Aumento do ataque de insetos que se desenvolvem sob essa manta orgânica;

- Camadas de resíduos espessas;

- Cobertura de cepas pelos resíduos, impedindo ou prejudicando sua brotação;

- Dificuldades no preparo do solo, na abertura do sulco ou de covas;

- Redução do pH do solo devido a decomposição da matéria orgânica. 
A quantidade de nutrientes nas folhas, nos ramos e na casca do eucalipto é bastante expressiva. O resíduo da exploração, quando mantido no campo, diminui o impacto da exportação e auxilia na fertilidade do solo. A composição química de nutrientes dos resíduos oriundos da colheita florestal é um importante fator na manutenção da qualidade da superfície do solo, evitando assim, a compactação do solo pelo maquinário industrial outro fator interessante é que a cobertura desses resíduos quando deixadas em campo facilita a interações entre trocas de nutrientes entre o sistema planta e atmosfera que depende exclusivamente de restos orgânicos para ocorrer. O valor nutricional dos resíduos de colheita florestal está apresentado na Tabela 3.

Tabela 3. Valores médios dos teores de minerais da madeira, casca, galhos e folhas, estimados por kg de material, por hectare

\begin{tabular}{|c|c|c|c|c|c|c|c|c|c|c|c|}
\hline \multicolumn{12}{|c|}{ Massa de nutriente por hectare } \\
\hline Nutriente & $\mathrm{N}$ & $\mathrm{P}$ & $\mathrm{K}$ & $\mathrm{Ca}$ & $\mathrm{Mg}$ & S & $\mathrm{Zn}$ & $\mathrm{Fe}$ & $\mathrm{Mn}$ & $\mathrm{Cu}$ & $\mathrm{B}$ \\
\hline Madeira & 105,86 & 8,53 & 201,61 & 25,84 & 6,94 & 47,93 & 0,16 & 1,21 & 0,98 & 0,21 & 0,92 \\
\hline Casca & 15,79 & 2,72 & 61,33 & 36,99 & 12,15 & 3,63 & 0,19 & 13,78 & 38,00 & 0,40 & 1,48 \\
\hline Galho & 8,37 & 1,16 & 14,99 & 11,50 & 4,40 & 1,21 & 0,41 & 8,47 & 24,26 & 0,65 & 1,78 \\
\hline Folha & 40,59 & 2,97 & 24,15 & 14,20 & 7,78 & 3,52 & 1,24 & 15,13 & 31,18 & 0,78 & 5,38 \\
\hline
\end{tabular}

Fonte: Adaptado de Castro et al. (2017).

Na Tabela 3 são apresentados os valores médios dos diferentes nutrientes encontrados nas partes das árvores, onde os elementos de interesse irão variar suas proporções de acordo com a parte coletada. Segundo Castro et al. (2017) a principal barreira para o aproveitamento dos resíduos da colheita florestal é a questão logística para o transporte da biomassa até a planta de cogeração devido ao seu alto volume. Dentre as alternativas para aproveitamento dos resíduos, tem-se a picagem ou produção de cavacos próximo ao talhão (área de produção de madeira) e enfardamento da biomassa. Dessa forma, consegue-se diminuir o volume do material a ser transportado.

Quanto às receitas adicionais geradas pela utilização de resíduos florestais e madeireiros, Santiago \& Rezende (2013) avaliaram a utilização de resíduos gerados por Eucalyptus spp. em uma grande empresa produtora no Brasil para geração de energia térmica e elétrica e demonstrou a possibilidade de uma receita adicional de cerca de US\$ 2,2 milhões por ano para a empresa. Simangunsong et al. (2019) observaram que seria criado um valor econômico de US\$19,0 por tonelada de resíduos de madeira caso a empresa vendesse esse material como lenha. Além disso, o valor econômico foi estimado em cerca de US\$ 29,6 por tonelada de resíduos de madeira caso eles fossem granulados, resultando em um aumento do valor econômico de $56 \%$.

Domingues-Tomaz et al. (2017) analisando 2 cenários para utilização da biomassa de resíduos de eucalipto proveniente de colheita florestal, relatam que nos processos de conversão dos resíduos em energia, geram-se cinzas, que é o material inorgânico do processo de conversão da biomassa. Os autores citam que a utilização de cinzas é muito interessante do ponto de vista de reaproveitamento nutrientes e correção do solo (Domingues-Tomaz et al., 2017). A análise do fluxograma dos resultados obtidos no estudo de Domingues-Tomaz et al. (2017) para a tomada de decisão acerca do melhor aproveitamento dos resíduos pode ser observada de acordo com a Figura 2. 
Figura 2. Fluxograma de decisão para entendimento do melhor produto direcionado ao mercado.

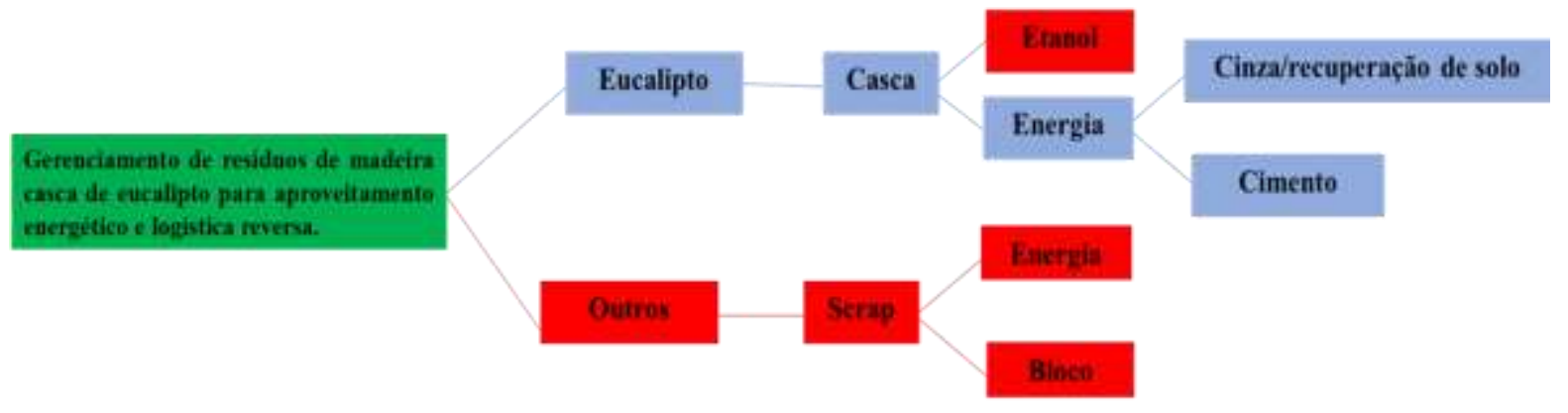

Fluxo aceito para o projeto

Fluxo descartado para o projeto

Fonte: Adaptado de Domingues-Tomaz et al. (2017).

Na Figura 2 é possível observar um fluxograma de decisão que pode auxiliar a tomada de decisão dos responsáveis técnicos das indústrias durante a definição de estratégias para o gerenciamento da madeira de eucalipto. Hansted (2020) caracterizando as cinzas residuais de uma caldeira no munícipio de Salto, interior do estado de São Paulo, verificou a presença de metais e óxidos já descritos na literatura. Os álcalis cáusticos e os óxidos de $\mathrm{Ca}, \mathrm{Mg}, \mathrm{K}, \mathrm{P}$ apresentam relação direta com o aumento no pH quando adicionados ao solo (Wons et al., 2018). Desta forma, essas cinzas apresentam real potencial para utilização quando o objetivo é alterar o pH baixo, ações melhorativas necessárias em solos ácidos, por exemplo (Shi et al., 2016). Hansted (2020) chama a atenção para o fato de esse tipo de cinzas não apresenta metais tóxicos o que possibilita a ampliação da utilização desse material para usos agrícolas, especificamente para a correção do solo, alternativamente à calagem convencional com gesso ou calcário. Nesse estudo, o autor também observou a presença de Fe e Al, porém em baixa proporção, o que não inviabilizaria a utilização dessas cinzas com aditivo em solos agricultáveis.

\section{Tecnologias de Aproveitamento de Resíduos de Colheita Florestal}

\subsection{Briquetagem}

Os principais problemas da utilização de resíduos industriais e florestais para produção de energia são, principalmente, a baixa densidade energética, as dimensões e volumes variados, a alta higroscopicidade e o teor de umidade desses materiais (Santos et al., 2013). Uma das formas de solucionar os problemas e melhorar as propriedades energéticas dos resíduos seria a sua densificação, ou seja, produção de materiais sólidos de com mais alta concentração de energia. Nessa categoria estão incluídos os briquetes e os pellets (Carvalho et al. 2013). Protásio et al. (2015) citam que os briquetes foram criados em função da demanda por um novo tipo de combustível compactado com alta densidade energética, viabilizando o transporte em maiores distâncias, a otimização do armazenamento e principalmente o uso em equipamentos modernos de queima.

Oliveira et al. (2017) analisando as propriedades energéticas, físicas e mecânicas de briquetes formados com resíduos de colheita florestal de Pinus sp., observaram valores excelentes da biomassa para a produção de energia, a saber, 0,83\% de cinzas, sendo o recomendado no máximo 1,5\% (Protásio et al., 2015). Também determinaram carbono fixo médio 17,24\%, sendo de $25 \%$ o valor recomendado para esse parâmetro, uma vez que valores elevados aumentam o tempo de residência do combustível dentro dos queimadores. Ainda, Oliveira et al. (2017) observaram densidade a granel de $1049,8 \mathrm{~kg}$ m 3 para os 
briquetes produzidos, ressalta-se que é considerado uma boa densidade, visto que a logística e transporte dependem dos espaços vazios nos briquetes. No estudo de Oliveira et al. (2017) concluíram que trabalhos que avaliem o potencial dos resíduos para a produção de energia são escassos de informações acerca da qualidade dos produtos produzidos. Porém os que foram produzidos apresentaram qualidade satisfatória para a utilização dos resíduos da colheita de Pinus.

\subsection{Peletização}

Pellets de biomassa florestal ou pellets de madeira são pequenos blocos cilíndricos, compactados e densos, resultantes da aglomeração de materiais lignocelulósicos, que são utilizadas na geração de energia na forma de calor ou eletricidade (Spanhol, 2015). Caraschi \& Garcia (2013) acrescentam ainda que os pellets são biocombustíveis renováveis produzidos a partir da biomassa agroflorestal, com baixo teor de umidade, forma homogênea e alta densidade energética. Além disso, é um produto natural, de fácil manuseio e estocagem. Os pellets são utilizados para a geração de energia térmica e elétrica em pequenas ou médias unidades geradoras. $\mathrm{O}$ uso dos pellets proporciona uma série de vantagens, quando comparado ao uso da madeira in natura, principalmente no tocante ao armazenamento, manuseio, aumento da densidade, poder calorífico, facilidade de transporte, uniformização do material e redução substancial da ação poluidora (Spanhol, 2015). Porém, a produção desse biocombustível necessita de normatização para garantir a quantidade e qualidade da energia requerida nos sistemas de geração para os quais o produto será destinado. A padronização das propriedades físicas, mecânicas e energéticas dos pellets é de extrema importância, tanto para emissão de laudos de qualidade, que na maior parte das vezes são requeridos pelos consumidores, tanto no mercado nacional quanto no internacional. Uma boa perspectiva para o produtor de pellets é que o consumo desse produto no mercado internacional vem crescendo a cada ano.

\subsection{Cavaqueamento ou chipping}

O cavaqueamento ou chipping consiste na transformação da biomassa em cavacos. A conversão de materiais lignocelulósicos de granulometria desuniforme e aleatória em cavacos permite solucionar problemas de manuseio, a sua redução e a homogeneização para utilização na geração de energia (Oro, 2015). Atualmente nas indústrias florestais existem duas formas de utilizar a biomassa residual de colheita florestal por cavaqueamento, sistema de árvores inteiras e de toras curtas (Oro 2015).

\subsubsection{Cavaqueamento de árvores inteiras}

Para o cavaqueamento da biomassa residual no sistema de colheita da madeira de árvores inteiras (full-tree), as árvores são cortadas pelo feller-buncher, e em seguida arrastadas por trator tipo skidder até a margem do talhão ou pátios intermediários, onde será realizado o processamento, ficando separados as toras e os resíduos (Figura 3). 
Figura 3. Cavaqueamento no sistema de árvores inteiras.

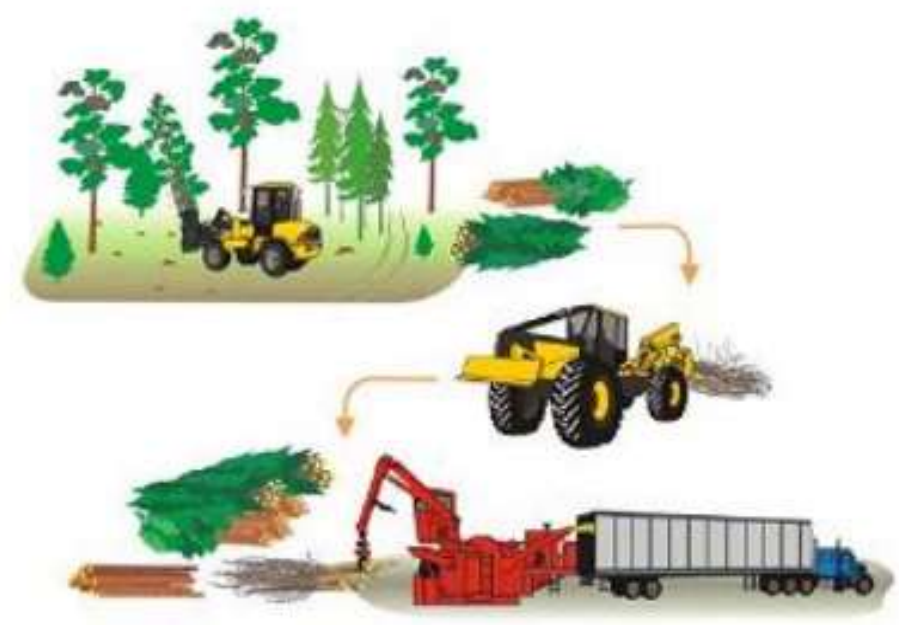

Fonte: Oro (2015).

Como ilustrado na Figura 3, o cavaqueador normalmente é posicionado na margem do talhão ou em pátios intermediários para realização do processamento dos resíduos diretamente sobre os veículos de transporte e levados então para a unidade de consumo (Oro, 2015).

\subsubsection{Cavaqueamento em toras curtas}

Na Figura 4 é mostrado o ciclo das operações de aproveitamento da biomassa residual no sistema de toras curtas, de acordo com Oro (2015). Este sistema envolve desde o transporte e processamento dos resíduos até a sua distribuição para os locais de queima e geração de energia.

Figura 4. Cavaqueamento de biomassa em sistema de colheita de toras curtas.

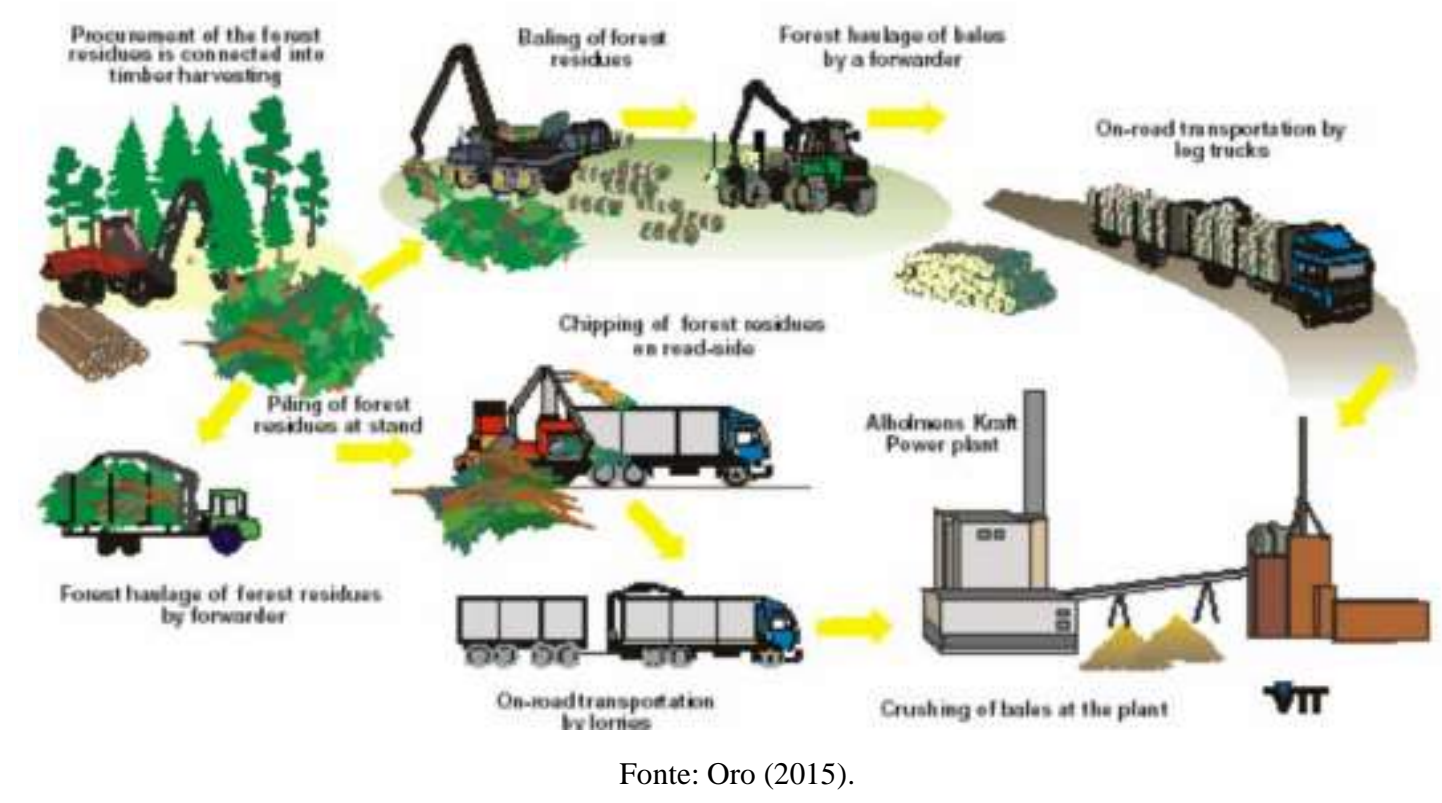


De acordo com a Figura 4, é possível observar que as atividades iniciam-se com a aglomeração dos resíduos em fardos pela enfardadeira e a posterior remoção dos fardos de resíduos ou somente dos resíduos para a margem da estrada com o auxílio do forwarder adaptado, onde ocorre então, o carregamento e transporte dos fardos para a indústria ou o cavaqueamento do material para posterior transporte dos cavacos para a indústria ou consumidor final.

\subsection{Produção de biochar}

Biochar ou biocarvão é um carvão de obtido de material vegetal que passou por processo de pirólise, decomposição térmica em ambiente com restrição total ou parcial de oxigênio. Os usos para o biochar são diversos, mas a mais citada é o de atuar positivamente no sequestro de carbono quando aplicado e imobilizando em solos agrícolas e florestais. É um material orgânico, que pode ser produzido a partir de inúmeros tipos de biomassa, como por exemplo, madeira, resíduos agrícolas, resíduos florestais ou industriais. A escolha da matéria prima para a formação do biochar deve depender da adequação deste material para o uso, conforme às características químicas, físicas, ambientais e disponibilidade (Han et al., 2020).

O biochar é constituído de cerca de $80 \%$ de carbono e menos de $0,1 \%$ de nitrogênio. A natureza porosa do biochar é potencialmente benéfica para aumentar a capacidade de retenção de água e densidade aparente dos solos onde esse material for incorporado. Também altera o cátion capacidade de troca e cor do solo e é o local de muitos fungos ectomicorrízicos (PageDumroese et al. 2017). O biochar pode ser usado para restaurar o solo, sendo especialmente recomendado para áreas onde há ou houve perda de matéria orgânica (Hansted 2020). Porém, o principal entrave para o aproveitamento dos resíduos florestais para conversação essa finalidade é o alto custo em logística de transporte para sua conversão via pirólise (Page-Dunroese et al. 2017). Estão sendo desenvolvidas novas técnicas de produção de biochar, sendo uma das mais promissoras as tecnologias de contêineres, que são consistem de equipamentos levados até as áreas de plantio e pirolisados no local, conforme será discutido nos próximos tópicos.

\subsubsection{Sistema de produção de Biochar queima de cortina e calor (Air curtain burner)}

Esses queimadores são projetados para o aproveitamento resíduos lenhosos como alternativa ao descarte por queima a céu aberto (estacas cortadas) e foram desenvolvidas para serem usadas perto de operações de colheita em larga escala e que geram grandes volumes de madeira. Inicialmente, os cavacos dos resíduos são secos a céu aberto, em seguida são pirolisados e por fim, são movidos no trado rotativo. As etapas de produção podem ser vistas de acordo com a Figura 5 (Page-Dumroese et al., 2017).

Figura 5. Processo de produção do biochar através da queima de cortina e calor. Onde: A) representa os resíduos de colheita florestal sendo coletados. B) Mini-forno sendo coberto para criar o biochar e C) Biochar formado no forno rotativo.

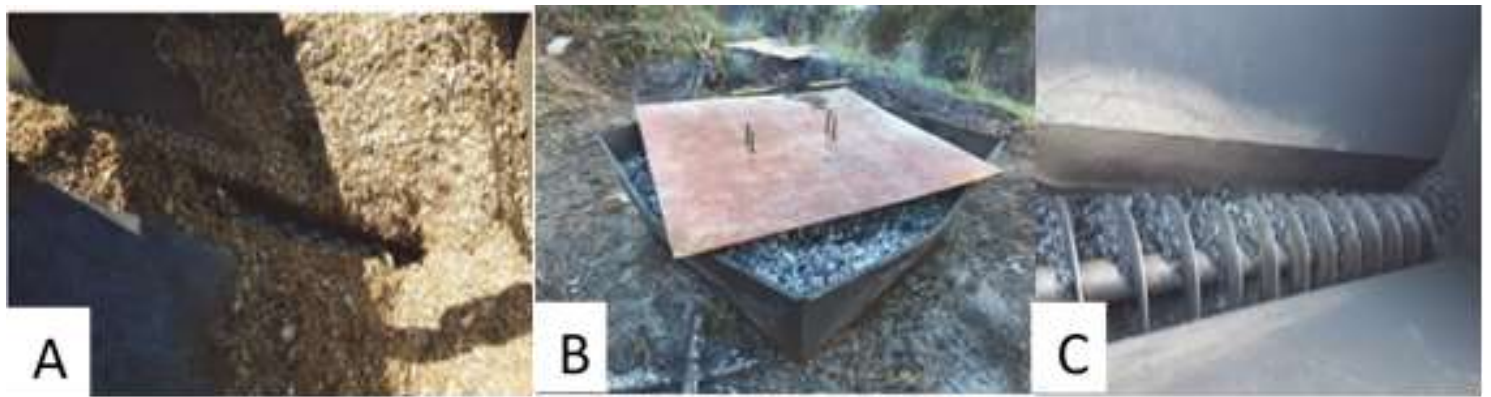

Fonte: Page-Dumroese et al. (2017). 
De acordo com as etapas apresentadas na Figura 5 é possível observar que o processo de produção de biochar envolve desde a coleta e processamento até o resfriamento do biochar, que, após estas etapas, poderá ser utilizado.

\subsubsection{Sistema contêiner}

É um sistema desenvolvido pelo Departamento de Agricultura dos Estados Unidos- USDA em 2005, no qual consiste em um contêiner automatizado que percorre o plantio, facilitando a coleta e a incineração da biomassa, que posteriormente é convertida em biochar. A Figura 6 ilustra a tecnologia desenvolvida.

Figura 6. Mini contêiner para incineração dos resíduos para geração de biochar.

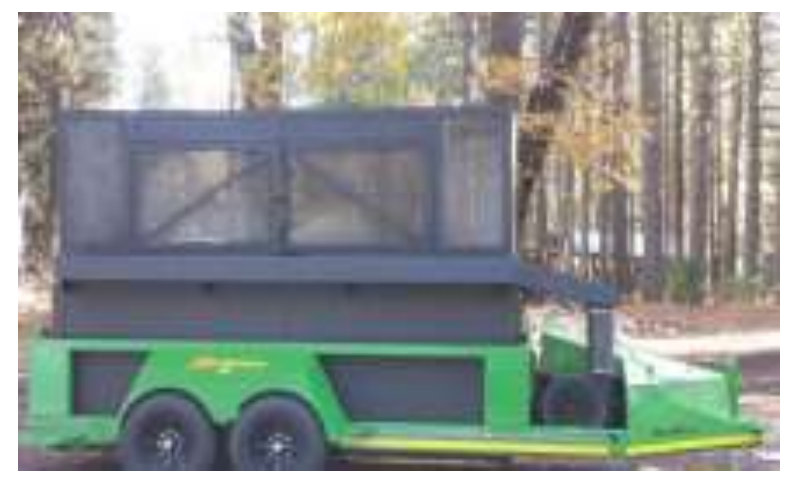

Fonte: USDA (2005).

Na Figura 6 é possível observar o contêiner automatizado, responsável pela incineração da biomassa e a sua transformação em biochar. Neste sistema, além das vantagens relacionadas ao tempo de transformação dos resíduos em biochar, é possível destacar a economia do processo, principalmente relacionado ao transporte do material e, posteriormente, o transporte do biochar para a utilização.

\section{Resíduos de Pinus e Eucalipto: Quantificação e Estimativas de Energia Disponível}

A área total de árvores plantadas no Brasil totalizou 7,83 milhões de hectares em 2018, mantendo-se praticamente estável em relação a 2017 (IBÁ 2020). Plantios de eucalipto ocupam 5,7 milhões de hectares desse total, enquanto as áreas com Pinus somam 1,6 milhões de hectares. Os dados em áreas plantadas correspondentes as espécies podem ser observadas de acordo com a Figura 7. 
Figura 7. Áreas de plantio no Brasil (2017 e 2018).

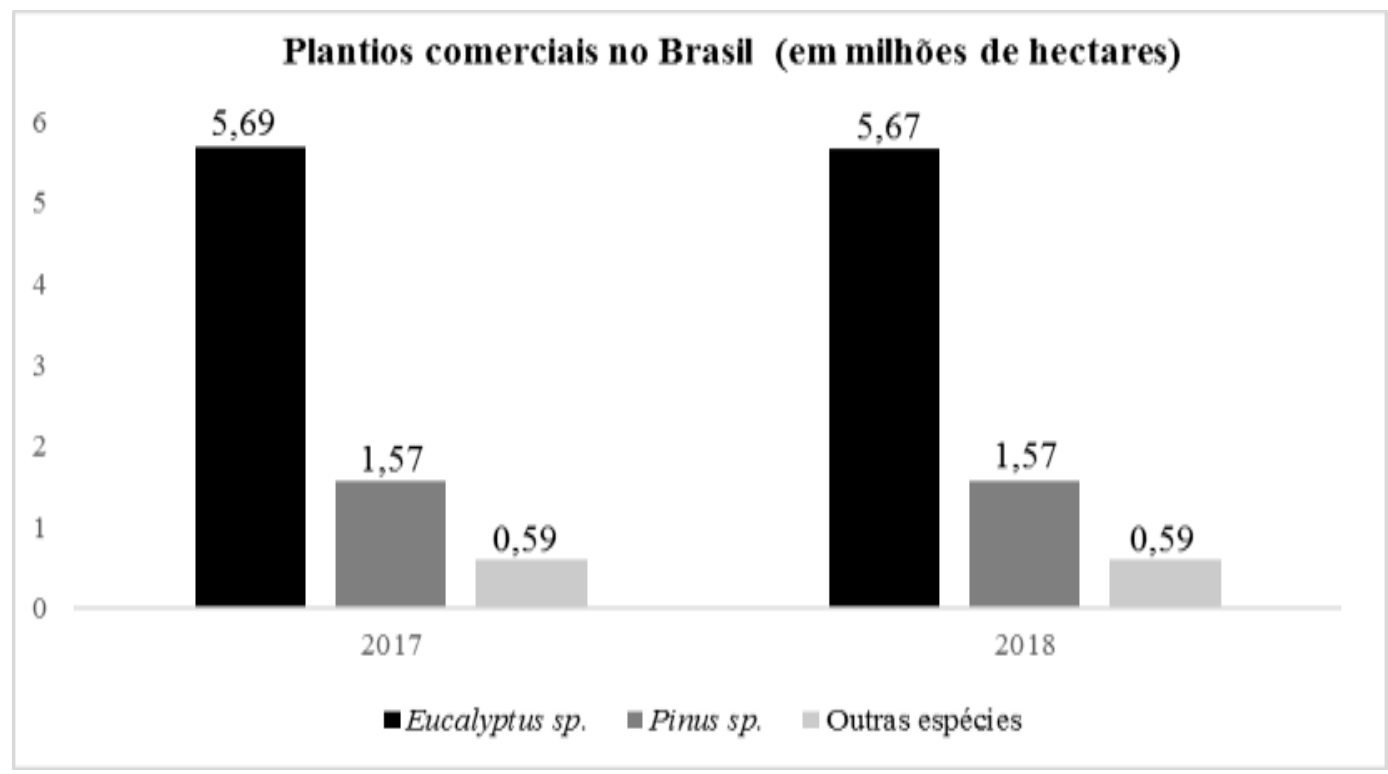

Fonte: Adaptado de Indústria Brasileira de Árvores-IBÁ (2020).

Na Figura 7 é possível observar o valor médio das diferentes áreas de florestas plantadas no Brasil. As florestas de Pinus e de Eucaliptos são significativamente importantes para o setor de celulose e papel, energia e madeira serrada, dentre outros usos. Porém, geram resíduos durante a colheita florestal que podem e devem ser reutilizados para finalidade energética. Pincelli et al. (2017) quantificando e estimando os resíduos de Pinus e eucalipto no município de Lençóis Paulista-SP em diferentes granulometrias, determinaram para as duas espécies, os seguintes totais de resíduos conforme mostrado nas Tabelas 4 e 5 .

Tabela 4. Quantificação do percentual dos componentes dos resíduos da colheita florestal de Eucalyptus grandis e Pinus caribaea var. hondurensis.

\begin{tabular}{cccc}
\hline Espécie & Madeira com casca (\%) & Casca solta (\%) & Folha ou acícula (\%) \\
\hline Eucalipto & 74,9 & - & 25,1 \\
Pinus & 74 & 8,6 & 17,4 \\
\hline
\end{tabular}

Fonte: Adaptado de Pincelli et al. (2017).

Os dados apresentados na Tabela 4 descrevem a porcetagem dos diferentes resíduos produzidos em florestas de Eucalipto e de Pinus. Os valores de estimativa proposta no estudo de Pincelli et al. (2017) levaram em consideração a produtividade total média para eucalipto com 7 anos como sendo 136,4 tha-1 e para Pinus foi considerado a produtividade de 11 anos no total de 112,7 tha 1. Os resultados da estimativa da quantidade de resíduos podem ser observados na Tabela 7. 
Tabela 5. Estimativa da quantidade de resíduos de colheita gerados por unidade de área e por árvore, teor de umidade e densidade a granel.

\begin{tabular}{cccccc}
\hline Espécie & Peso dos resíduos & $\begin{array}{c}\text { Proporção de produção } \\
(\%)\end{array}$ & Teor de umidade (\%) & Densidade a granel (\%) \\
\hline t ha & & Kg ha $^{-1}$ & & & $193 \mathrm{a}$ \\
\hline Eucalipto & $8,2 \mathrm{~b}$ & $4,9 \mathrm{~b}$ & $6,0 \mathrm{~b}$ & $10,4 \mathrm{~b}$ & $131 \mathrm{~b}$ \\
\hline
\end{tabular}

Fonte: Adaptado de Pincelli et al. (2017).

$\mathrm{Na}$ Tabela 5 são apresentados os pesos e outras características físicas dos resíduos produzidos em florestas de Eucalipto e de Pinus. De acordo com os resultados obtidos pelos autores, os resíduos de colheita florestal perfazem um total de 6,1 e 11 t ha-1 de resíduos lenhosos após a colheita madeireira para as culturas de Pinus e eucalipto, respectivamente. Isto representa uma reserva energética de biomassa estimada em 4,9 milhões de toneladas de resíduos lenhosos na cultura de eucalipto (considerando o ciclo de 7 anos) e de 1,5 milhões de toneladas na cultura de Pinus (considerando o ciclo de 12 anos).

\section{Exportação de Nutrientes Pela Colheita Florestal}

Como já mencionado anteriormente os nutrientes da biomassa residual são importantes para a qualidade nutricional do solo. No entanto, sabe-se que a quantificação dos nutrientes nos componentes da biomassa de um povoamento permite avaliar a magnitude dos reflexos que seriam causados pela intervenção do homem ou por fenômenos naturais ocorridos no ecossistema. A saída de nutrientes via exportação deve ser um componente levado em consideração por parte das empresas, na hora do planejamento. Tal preocupação evita que haja diminuição de produtividade com as rotações futuras e contribui para o manejo sustentável, pois a exportação de nutrientes, principalmente do Ca, é elevada devido à colheita da madeira com casca (Caldeira et al. 2014).

Em um estudo realizado por Caldeira et al. (2014), analisando a exportação de nutrientes em um plantio de Acacia mearnsii, as seguintes exportações de macronutrientes são reportadas: 73\% do C, 43\% do N, 44\% do P, 51\% do K, 71\% do Ca, $59 \%$ do $\mathrm{Mg}, 55 \%$ do S e $45 \%$ do B, $47 \%$ do $\mathrm{Cu}, 19 \%$ do Fe, $46 \%$ do Mn e $53 \%$ do Zn, para os micronutrientes. Caldeira et al. (2014) constataram que ocorreu para os macronutrientes que a conservação dos demais resíduos no sítio é de grande importância, pois conserva grande quantidade de micronutrientes, sendo que para o B, Cu, Fe e Mn essa conservação está cima de 50\%. Os resultados encontrados na pesquisa de exportação dos nutrientes reportado por Caldeira et al. (2014) de acordo com a Figura 8 . 
Figura 8. Percentagem de exportação de macronutrientes e micronutrientes com a colheita da madeira e da casca de Acacia mearnsii aos 4 anos de idade.

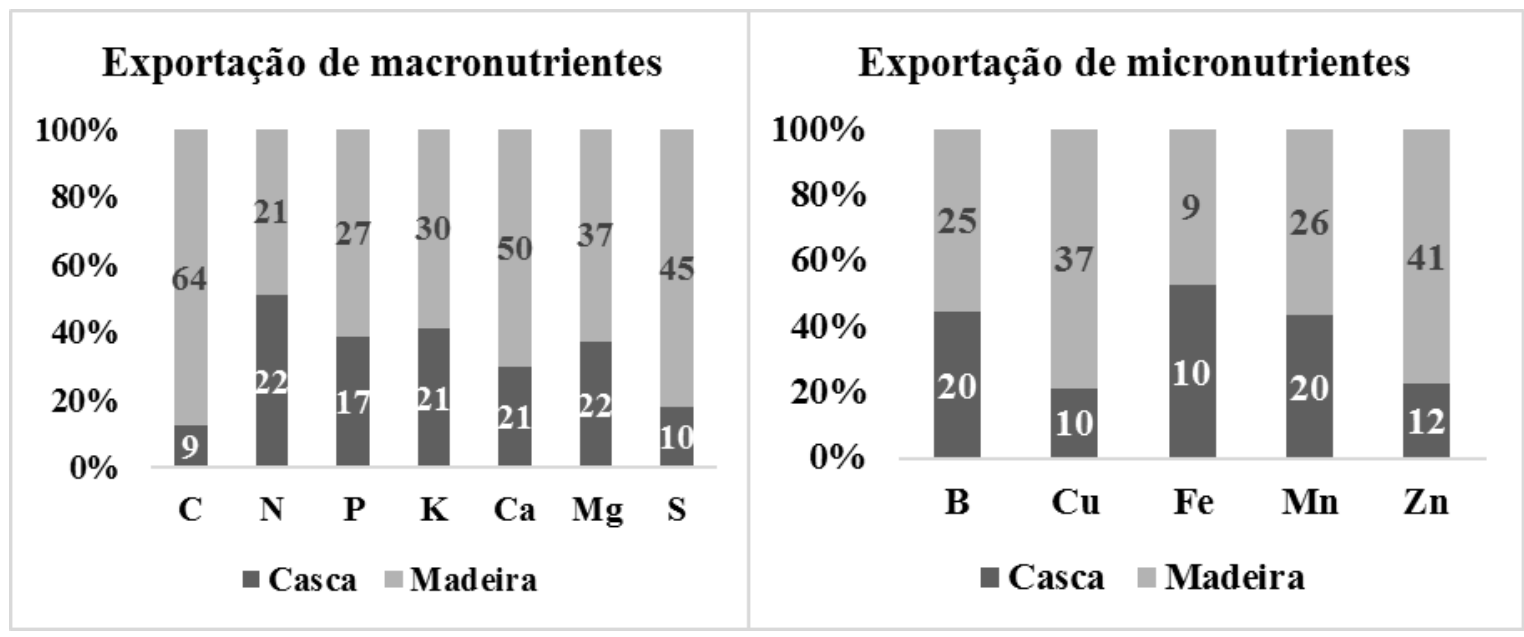

Fonte: Adaptado de Caldeira et al. (2014).

Na Figura 8 são apresentados os dados referentes à exportação de macros e micronutrientes, tanto nas cascas quanto na madeira de árvores de Acacia mearnsii. Os resultados apresentados pelos autores citados acima sugerem que o correto manejo dos resíduos traz resultados positivos para o solo. Contudo, eles ressaltam que o emprego de um manejo não planejado resulta em drásticas exportações, que posteriormente resultam em desequilíbrios e necessidade de correção do solo para um novo ciclo de plantio. Frantz et al. (2015), estudando a influência da exportação de nutrientes pela colheita para Eucalyptus grandis x Eucalyptus urophylla aos 54 meses de idade, avaliaram os macronutrientes N, P e K em uma plantação localizada em Alegrete-RS. Na Tabela 6 são mostradas as quantidades de nutrientes exportadas pela colheita da madeira comercial sem casca do tronco de Eucalyptus urograndis.

Tabela 6. Quantidade de macronutrientes exportados na biomassa da madeira do tronco de Eucalyptus urograndis no Bioma Pampa - RS.

\begin{tabular}{ccc}
\hline Elemento & \multicolumn{2}{c}{ Quantidade } \\
\hline $\mathbf{N}$ & Kg ha $^{\mathbf{1}}$ & Kg ha $^{-\mathbf{1}} \mathbf{a n o}^{\mathbf{1}}$ \\
\cline { 2 - 3 } $\mathbf{P}$ & 118,4 & 26,31 \\
$\mathbf{K}$ & 6,4 & 1,42 \\
& 150,9 & 33,5 \\
\hline
\end{tabular}

Fonte: Adaptado de Frantz et al. (2015).

Na Tabela 6 são apresentados os valores médios da exportação de três macronutrientes (Nitrogênio, Fósforo e Potássio) na madeira do tronco de Eucalyptus urograndis. Os resultados do estudo de Frantz et al. (2015) indicam que o corte e colheita da madeira de Eucalyptus urograndis aos 4,5 anos implicam em grande remoção de N, P e K, o que pode se refletir em custos mais elevados com adubação nos ciclos seguintes. Por isso, os autores recomendaram que para haver redução em tal exportação, ciclos mais longos com pelo menos 7 ou 8 anos para evitar grandes perdas de nutrientes. Com idades de rotação mais altas, há tempo de haver a reciclagem de nutrientes para o solo. 


\section{Considerações Finais}

A colheita florestal é uma importante prática dentro do setor florestal. Entretanto, quando não planejada criteriosamente gera perdas para a empresa ou negócio florestal. Fica evidente que o aproveitamento dos resíduos dentro da própria empresa florestal é interessante e tecnicamente viável, porém necessita de um planejamento técnico para utilização, visto que se for utilizado todo resíduo de uma vez resultará em uma falta de nutriente no solo e aumento da compactação do solo, necessitando um correto manejo.

Trabalhos futuros podem ser realizados buscando o desenvolvimento de uma estratégia que as empresas florestais poderiam adotar com o intuito de quantificar os resíduos florestais, o que pode fornecer subsídios para a análise operacional, quantificação e qualificação do material, que pode ser aproveitado para a sua comercialização. Nesta perspectiva, toda a contribuição que favoreça a análise operacional resultará em um aperfeiçoamento das possibilidades de rendimento negocial destes resíduos, gerando desenvolvimento, tanto para a área industrial, quanto para o setor acadêmico, no desenvolvimento de novas tecnologias e rotas de reaproveitamento.

\section{Referências}

ANEEL. (2016). Banco de Informações de Geração: Capacidade de Geração do Brasil. http://www2.aneel.gov.br/aplicacoes/capacidadebr asil/capacidadebrasil.cfm.

Ayer, N. W. \& Dias, G. (2018). Supplying renewable energy for Canadian cement production: Lifecycle assessment of bioenergy from forest harvest residues using mobile fast pyrolysis units. Journal Clean Production, 175 (20), 237-250.

Borges, A. C. P., Silva, S. S., Alves, C. T., \& Torres, A. E. (2016). Renewable energy: a contextualization of the biomass as power supply. REDE-Revista eletronica do PRODEMA, 10, 23-36.

Buonocore, E., Hayha, T., Paletto, A., \& Franzase, P. P. (2014). Assessing environmental costs and impacts of forestry activities: a multi-method approach to environmental accounting. Environment Engenieer, 271(10), 10-20.

Braz, R. L., Nutto, L., Brunsmeier, M., Becker, G., \& Silva, D. A. (2014). Resíduos da colheita florestal e do processamento da madeira na Amazônia- Uma análise da cadeia produtiva. Journal of biotechnology and Biodiversity, 5 (2), 168-181.

Caldeira, M. V. W., Godinho, T. O., Saidelles, F. L. F., Vieira, M., Schumacher, M. V., \& Castro, K. C. (2014). Exportação de carbono e nutrientes pela colheita de Acacia mearnsii De Wild aos quatro anos de idade na Depressão Central, RS. Comunicata Scientiae, 5(1), 68-74.

Carvalho, A. M. M. L., Pereira, B. L. C., \& Souza, M.M. (2013). Produção de pellets da madeira. In: Santos, F., Colodette, J., \& Queiroz, J. H. (Eds.) Bioenergia \& Biorrefinaria: cana de açúcar e espécies florestais. Viçosa: UFV: Viçosa, 380400.

Castro, A. F. N. M., Castro, R. V. O., Carneiro, A. C. O., Carvalho, A. M. M. L., Silva, C. H. F., Cândido, W. L., \& Santos, R. C. (2017). Quantification of forestry and carbonization waste. Renewable energy, 103(4), 432-438.

Chang, K. H., Lou, K. R., \& Ko, C. H. (2019). Potential of bioenergy production from biomass wastes of rice paddies and forest sectors in Taiwan. Journal Clean Production, 206(1), 460-476.

Dulys-Nusbaum, E., Klammer, S. S. H., \& Switon, S. M. (2019). How willing are different types of landowner to supply hardwood timber residues for bioenergy? Biomass Bioenergy, 122 (3), 45-52.

FAO. (2018). Wood energy. http://www.fao.org/forestry/energy/en/.

Ferreira, J. C., Stahelin, T. S. F., Jesus, M. S., Muñiz, G. I. B., Brand, M. A., \& Freitas, T. P. (2019). Estimation of the ofter of forest biomass in populations of Pinus taeda L. after cultural interventions. Ciência Florestal, 29(3), 1-8.

Foelkel, C. (2015). Casca da árvore de Eucalipto. Aspectos morfológicos, fisiológicos, florestais, ecológicos, e industriais, visando a produção de celulose e papel. Eucalyptus online Book \& Newsletter, https://www.eucalyptus.com.br/capitulos/capitulo_casca.pdf.

Frantz, B. C., Guimarães, C. C., Schumacher, M. V., Souza, H. P., \& Dick, G. (2015). Exportação de nutrientes através da colheita de Eucalyptus urophylla x Eucalyptus grandis no sul do brasil. http://www.congressoeucalipto.com.br/trabalhos_a/FRANTZ_Bernardo_Corso.pdf.

Grodsky, S. M., Moorman, C. E., Fritts, S. R., Hazel, D. W., Homyack, J. A., Castleberry, S. B., \& Wigley, T. B. (2016). Supplying renewable energy for Canadian cement production: Lifecycle assessment of bioenergy from forest harvest residues using mobile fast pyrolysis units. Forest Ecology Manager, 379, 91-101.

Hansted, A. L. S. (2020). Aproveitamento de cinzas de caldeira para calagem do solo. Tese (Doutorado em energia da agricultura), Universidade Estadual Paulista, Botucatu, SP, Brasil.

IBÁ. (2020). Indústria Brasileira de Árvores. Relatório 2020. Brasília: IBÁ. 
ICMBIO. (2014). Aproveitamento de resíduos do manejo florestal garante renda para comunidade e proteção para a floresta nacional. https://www.icmbio.gov.br/praticasinovadoras/todas-as-praticas/175-pratica-2014-20.html

Jin, E., \& Sutherland, J. W. (2018). An integrated sustainability model for a bioenergy system: Forest residues for electricity generation. Biomass Bioenergy. $119,10-21$.

Jonsson, R. (2013). How to cope with changing demand conditions - the Swedish forest sector as a case study: an analysis of major drivers of change in the use of wood resources. Canadian Journal Forestry Research, 43(999), 405-418.

Kraxner, F., Nordstrom, E. M., Havlík, P., Gusti, M., Monsier, A., Frank, S., Valin, H., Fritz, S., Fuss, S., Kindermann, G., McCallum, I., Khabarov, N., Bottcher, H., See, L., Aoki, K., Schmid, E., Máthé, L., \& Obersteiner, M. (2013). Global bioenergy scenarios-future forest development, land-use implications, and trade-offs. Biomass Bioenergy. 57, 86-96.

Lahr, F. A. R., Nogueira, M. C. J. A., Araújo, V. A., Vasconcelos, J. S., \& Christoforo, A. L. (2017). Physical-mechanical characterization of Eucalyptus urophylla wood. Engenharia Agrícola, 37(5), 900-906.

Lauri, P., Kallio, M. I., \& Schneider, U. A. (2012). Price of CO2 emissions and use of wood in Europe. Forest Policy Economics. $15,123-131$.

LIPPEL (2014). Resíduos Florestais: Um grande potencial para geração de energia. https://www.lippel.com.br/noticias/residuos-florestais-um-grandepotencial-para-geracao-de-energia

Motghare, K. A., Rathod, A. J., Wasemar, K. L., \& Labhsetwar, N. K. (2015). Comparative study of different waste biomass for energy application. Journal Waste Manager. 47, 40-45.

Ribeiro,R. B. S. (2013) Quantificação e valoração de resíduos da colheita florestal nacional dos Tapajós. Dissertação (Mestrado em Ciência Florestal), Universidade Federal de Viçosa, Viçosa, MG, Brasil.

Roque, R. M., Tenorio, C., \& Oporto, G. (2019). Short rotation wood crops in Latin American: A review on status and potential uses as biofuel. Energies. 12, $705-725$.

Oliveira, F. L. R., Cabacinha, C. D., Tuffi, L. D. S, Barroso, D. G., Júnior, A. S., Brant, M. C., \& Sampaio, R. A. (2015). Crescimento inicial de eucalipto e acácia, em diferentes arranjos de integração lavoura-pecuária-floresta. Cerne. 21(2), 227-233.

Oliveira, L. H., Barbosa, P. V. G., Lima, P. A. F., Yamaji, F. M., \& Sette-Junior, C. R. (2017). Aproveitamento de resíduos madeireiro de Pinus sp.com diferentes granulometrias para a produção de briquetes. Revista de Ciências Agrárias. 40(3), 683-691.

Oro, D. (2015). Análise técnica de um cavaqueador e caracterização energética de cavacos de biomassa de colheita de madeira. Dissertação (Mestrado em Ciência Florestal), Universidade Estadual do Centro Oeste, Irati, PR, Brasil.

Page-Dumroese, D. S., Busse, M. D., Archuleta, J. G., McAvoy, D., \& Roussel, E. (2017). Methods to reduce forest residue after timber harvesting and produce black carbon. Scientica. $1-9$.

Pereira, A. S., Shitsuka, D. M., Parreira, F. J. \& Shitsuka, R. (2018). Metodologia da Pesquisa Científica. UFSM NTE.

Pincelli, A. L. S. M., Moura, L. F., \& Brito, J. O. (2017). Quantificação dos resíduos da colheita em florestas de Eucalyptus grandis e Pinus caribaea var hondurensis. Scientia Forestalis, 45 (115), 519-526.

Protásio, T. P., Trugilho, P. F., Siqueira, H. F., Melo, I. C. N. A., Andrade, C. R., \& Guimarães-Junior, J. B. (2015). Caracterização energética de pellets in natura e torrificados produzidos com madeira residual de Pinus. Pesquisa Florestal Brasileira, 35 (84), 435442.

Rodrigues, C. K. (2018). Colheita e transporte florestal. Curitiba.

Santiago, F. L. S., \& Rezende, M. A. (2013). Aproveitamento de resíduos florestais de Eucalyptus na indústria de fabricação de celulose para geração de energia térmica e elétrica. Energia na Agricultura, 29 (4), 241-253.

Santos, F. (2013). Bioenergia \& Biorrefinaria: cana de açúcar \& espécies florestais. Viçosa.

Schwerz, F., Eloy, E., Elli, E. F., \& Caron, B. O. (2019). Reduced planting spacing increase radiation use efficiency and biomass for energy in black wattle plantations: Towards sustainable production systems. Biomass and Bioenergy. 120, 229-239.

Sette- Junior, C. R., Hansted, A. L. S., Novaes, E., Lima, P. A. F., Rodrigues, A. C., Santos, D. R. S., \& Yamaji, F. M. (2018). Energy enhancement of the eucalyptus bark by briquette production. Industrial Crops Products, 122, 209-213.

Shi, R., Li, J., Jiang, J., Liu, Y., Xu,R., \& Qian, W.(2016). Characteristics of biomass ashes from different materials and their ameliorative effects on acid soils. Journal of Environmental Sciences, 55, 294-302.

Simangunsong, B. C. H., Silalahi, G. S. J., Maulana, M. D. G., Sitanggang, V. J., Manurung, E. G. T., Elias, E., \& Tambunan, A. H. (2019). Economic value of wood processing mill residues as feedstock for bioenergy in Indonesia. Journal Japonese Institut Energy. 98,110- 114.

Spanhol, A., Nones, D. L., Kumabe, F. J. B., \& Brand, M. A. (2015). Qualidade dos Pellets de biomassa florestal produzidos em Santa Catarina para geração de energia. Floresta. 45(4), 833-844.

Thiffault, E., Béchard, A., Paré, D., \& Allen, D. (2015). Recovery rate of harvest residues for bioenergy in boreal and temperate forests: A review. Wires Energy and Environment. 4, 429-451.

USDA (2005). The use of air curtain destructors for fuel reduction and disposal. https://www.fs.fed.us/t-d/pubs/html/05511303/05511303.html. 
Research, Society and Development, v. 10, n. 2, e4410212175, 2021

(CC BY 4.0) | ISSN 2525-3409 | DOI: http://dx.doi.org/10.33448/rsd-v10i2.12175

Tomaz, F. D., Souza, G. V., Silva-Junior, E. R., \& Ribeiro, A. S. (2017). Destinação e aproveitamento de resíduo florestal da colheita de eucalipto. https://www.saneamentobasico.com.br/destinacao-residuo-florestal/.

World Health Organization-WHO (2016). Burning Opportunity: Clean Hou-sehold Energy for Health, Sustainable Development, and Wellbeing of Women and Children. https://apps.who.int/iris/bitstream/handle/10665/204717/9789241565233_eng.pdf?sequence=1\&isAllowed=y

Wons, W., Rzepa, K., Reben, M., Murzyn, P., Sitarz, M., \& Olejniczak, Z. (2018). Effect of thermal processing on the structural characteristics of fly ashes. Journal of Molecular Structure, 1165, 299-304. 